\title{
PANDANGAN FUQAHA MUTAQADDIMĪN DAN MUTA'AKHKHIRĪN MENGENAI ISU AKAD NIKAH SECARA ATAS TALIAN
}

\section{Mutaqaddimīn and Muta'akhkhirīn's Views on the Issue of Online Marriage Contract}

\author{
Ahmad Uzair Izzuddin Ismail* \\ Raihanah Azahari ** \\ Zakiul Fuady Muhammad Daud***
}

\begin{abstract}
Marriage is considered a sacred contract that justify the relationship between a man and a woman. For that reason, the practice of it must abide by the predefined terms and regulations to ensure it is legal according to the Islamic law. Under normal circumstances, solemnization is done based on the defined procedures that obey the pillars of marriage, namely formal exchange of $\bar{\imath} j \bar{a} b$ and qabūl, presence of two witnesses, the woman's guardian, and both the groom and bride. However, along with the
\end{abstract}

* PhD Candidate, Department of Fiqh and Usul, Academy of Islamic Studies, Universiti of Malaya, 50603, Kuala Lumpur. ahmaduzairizzuddin@gmail.com

** Associate Professor, Department of Fiqh and Usul, Academy of Islamic Studies, University of Malaya, 50603, Kuala Lumpur. raihan@um.edu.my (Corresponding Author)

*** Lecturer, Department of Tarbiyah, Sekolah Tinggi Agama Islam Negeri (STAIN), Gajah Putih Takengon Aceh Tengah 24519, Aceh, Indonesia. zakiul_fuady@yahoo.com 
convenient technological advances, there are a few mechanisms used to tie the marriage knot online. The practice of tying the knot online has been used widely, specifically during the time of Covid-19 pandemic. Following this, the validity of online solemnization has become a topic discussed among the scholars. This article discusses the viewpoints of Islamic jurists (fuqaha') including the mutaqaddimin and muta'akhkhirin regarding the validity of online solemnization. This qualitative research uses literature review and documentation as the method to collect all the data needed. The research found that some of the muta'akhkhirin jurists necessitate online solemnization, given that the practice of it obey the defined terms, and some do not. While majority of mutaqaddimin jurists, except for Hanafi jurists, show tendency in not allowing online solemnization.

Keywords: Marriage, Nikah, Akad, Mutaqaddimīn and Muta'akhkhirin, Online Solemnization

\section{PENGENALAN}

Perkembangan teknologi telah memberi banyak manfaat dalam mencukupkan dan mempermudahkan urusan kehidupan harian manusia. Walaubagaimanapun, perkembangan teknologi haruslah diselarikan dengan syariat Islam berasaskan mentauhidkan Allah SWT dan mentaati segala perintah serta menjauhi segala laranganNya. ${ }^{1}$ Dalam konteks semasa, timbul pelbagai persoalan baru terhadap hukum fiqh sejajar dengan perkembangan teknologi, antaranya adalah pernikahan secara dalam talian atau nikah online. Isu ini tidak pernah dibincangkan secara jelas oleh fuqaha mutaqaddimin memandangkan teknologi rangkaian internet belum wujud pada masa lalu. Justeru, ijtihad yang dilakukan fuqaha muta'akhkhirīn telah mencetuskan perdebatan dalam menentukan kesahihan kaedah ini. Meskipun begitu, perbahasan oleh para

Wan Mohamed Radzi, C., \& Bakar, O., "Teknologi Menurut Perspektif Barat dan Islam,” Jurnal Usuluddin 3 (1996), 151. 
fuqaha mutaqaddimin yang menjurus ke arah perbincangan ini masih boleh dijadikan kayu ukur untuk membandingkan pandangan mereka dengan fuqaha muta'akhkhirīn.

Berdasarkan penelitian terhadap beberapa kajian dan penulisan mengenai isu ini, konsep akad nikah secara atas talian sememangnya telah dibincangkan dengan terperinci. Kebanyakan penulis menghubungkan perbahasan konsep akad nikah dari sudut rukun dan syarat dengan kaedah pelaksanaan akad nikah secara atas talian. Perbahasan-perbahasan yang dihuraikan cuba dikaitkan seboleh mungkin dengan teori-teori yang dikemukakan oleh para fuqaha silam terutamanya berkaitan dengan perbahasan mengenai syarat ìjāb dan qabūl, ittiḩād al-majlis dan saksi yang buta atau pekak. Namun, dalam masalah pernikahan secara panggilan suara dan sidang video, perbahasan lebih ditumpukan kepada pendapat dan hujah daripada kalangan fuqaha muta'akhkhirin.

Memandangkan akad nikah secara atas talian boleh dilangsungkan dalam medium yang pelbagai, masing-masing mengambil pendekatan tersendiri dalam mengungkapkan idea mereka. Misalnya, 'Abd al-Rahīm Șāliḥīi dalam tulisan beliau hanya menghuraikan satu kaedah iaitu akad nikah melalui e-mel, sementara 'Abd al-Ilāh bin Mazrū' al-Mazrū‘3 menghuraikan dua kaedah iaitu melalui percakapan (al-mukhätabah) dan tulisan (al-kitābah). Mufĩdah 'Abd al-Wahhāb Muhammad Ibrāhīm ${ }^{4}$ dan Muhammad Azwar Kamaruddin ${ }^{5}$ pula masing-masing menyebutkan tiga kaedah dalam melangsungkan akad nikah secara atas talian. Mufidah dalam penulisan beliau menyenaraikan tiga kaedah iaitu melalui faks (dan medium seumpamanya yang

2 Șāliḥ̄i, 'Abd al-Raḥ̄m, "In'iqād al-Ziwāj bi al-Barīd al-Iliktrūn̄̄ Dirāsah Muqāranah Bayna al-Fiqh al-Islāmī wa al-Qānūn alJazā’ir̄̄”, Majallah al-Dafātir al-Siyāsah wa al-Qānūn (Journal of Politic and Law) 7 (2012), 189-196.

3 'Abd al-Ilāh bin Mazrū' al-Mazrū', 'Aqd al-Ziwāj 'Abr al-Intarnit (t.t.p.: t.p., t.t.).

4 Mufīdah 'Abd al-Wahhāb Muḥammad Ibrāhīm, "Hukm Ijrā' 'Aqd al-Nikāḥ 'Abr al-Wasā’il al-Iliktrūniyyah al-Ḥadīthah," dalam Majallah Kulliyah al-Syarī'ah wa al-Qanūn, Jāmi'ah al-Azhar, vol. 20, no. 2 (2018), 1219-1248.

5 Kamaruddin, M.A., "Marriage Contact Using The Internet," Malaysian Journal of Syariah and Law 7 (2018), 227-258. 
menggunakan tulisan), telefon (dan medium seumpamanya yang menggunakan suara), dan internet yang merujuk kepada panggilan video, begitu juga Kamaruddin menyebutkan kaedah akad nikah melalui tulisan, percakapan dengan suara dan juga komunikasi yang merangkumi suara dan video secara serentak. Justeru, secara keseluruhannya, akad nikah secara atas talian boleh berlaku sama ada secara mesej, panggilan suara, ataupun sidang video seperti mana akan dijelaskan selepas ini.

Berdasarkan analisis terhadap penulisan-penulisan tersebut, didapati masing-masing telah membincangkan perbahasan fuqaha sama ada yang mengharuskan akad nikah secara atas talian atau menolaknya dengan mengemukakan dalil dan hujah masingmasing. Walau bagaimanapun, dapatan kajian menunjukkan bahawa tidak semuanya sehaluan dalam menyatakan kecenderungan masing-masing. Mufidah, 'Abd al-Ilāh dan Șāliḥ̄ masing-masing didapati menerima keharusan pernikahan secara atas talian, dengan syarat ia hanya terhad kepada pihak yang tidak boleh melakukan akad dengan cara biasa. Kamaruddin pula menolak keabsahan pernikahan dengan kaedah ini, meskipun di akhirnya beliau bersetuju bahawa kelonggaran boleh diberikan hanya pada kaedah akad nikah secara sidang video bagi mereka yang tidak boleh berada dalam satu majlis.

Dengan mengambil kira penulisan-penulisan yang telah ada, masih belum ada penulisan yang membandingkan pandangan fuqaha mutaqaddimin dan fuqaha muta'akhkhirin mengenai isu ini. Justeru, artikel ini akan membincangkan pendapat keduadua golongan fuqaha serta cuba untuk membandingkan pendapat antara mereka dan seterusnya menyimpulkan pandanganpandangan tersebut terhadap isu ini.

\section{PERNIKAHAN DALAM ISLAM}

Nikah merupakan sebuah akad yang menghalalkan persetubuhan antara lelaki dan wanita selagi wanita tersebut bukanlah haram dikahwini sama ada dari segi keturunan, saudara susuan ataupun perkahwinan. ${ }^{6}$ Ia disyariatkan oleh Allah SWT kepada

$6 \quad$ Al-Zuhaylī, Wahbah, al-Fiqh al-Islāmī wa Adillatuh (Damsyiq: Dār al-Fikr, 1985), 7: 29. 
manusia sebagai satu wasilah untuk menjaga hawa nafsu dengan menghalalkan hubungan sebagai suami isteri di samping menjaga keturunan dan nasab keluarga. Ia disyariatkan berdasarkan firman Allah SWT:

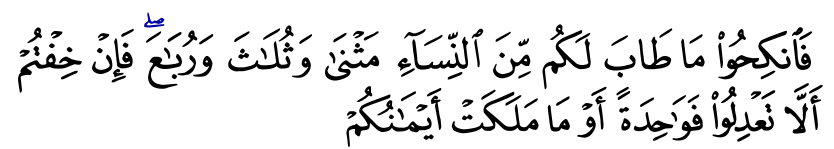

"Maka berkahwinlah dengan sesiapa yang kamu berkenan dari perempuan-perempuan: dua, tiga atau empat. Kemudian jika kamu bimbang tidak akan berlaku adil (di antara isteri-isteri kamu) maka (berkahwinlah dengan) seorang sahaja, atau (pakailah) hamba-hamba perempuan yang kamu miliki."

(Surah al-Nisā', 4: 3)

Pensyariatan perkahwinan juga bertujuan memastikan kelangsungan hidup manusia dan membina institusi keluarga sejahtera yang merupakan salah satu komponen daripada masyarakat. ${ }^{7}$ Malahan, Rasulullah SAW sendiri menggalakkan umat Baginda daripada kalangan pemuda-pemuda yang berkemampuan untuk berkahwin menerusi sabda Baginda SAW dalam sebuah hadis:

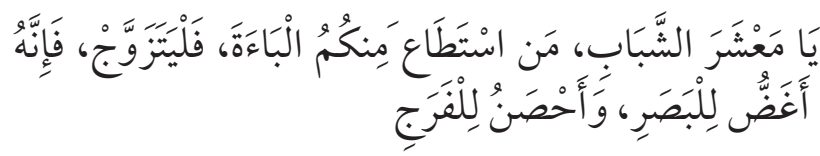

"Wahai para pemuda, barangsiapa antara kalian yang berkemampuan, maka berkahwinlah, maka sesungguhnya ia lebih berkesan menundukkan

$7 \quad$ Ibid., 31 


\section{pandangan dan lebih menjaga kemaluan." 8}

Dalam melangsungkan perkahwinan, ia tertakluk kepada beberapa rukun dan syarat yang mesti dipenuhi untuk mengesahkan akad tersebut. Perbahasan dalam menetapkan rukun dan syarat bagi akad nikah pula berbeza antara mazhab-mazhab yang muktabar. Misalnya, para fuqaha Hanafiyah mengatakan bahawa rukun nikah hanyalah dua perkara iaitu $\bar{l} j \bar{a} b$ dan qabū sementara jumhur fuqaha sepakat dalam empat rukun nikah iaitu șighah (merangkumi ìjāb dan qabül), pasangan lelaki, pasangan wanita dan juga wali. ${ }^{9}$ Tanpa salah satu daripada rukun dan syarat tersebut akan menyebabkan akad nikah tidak sah atau rosak.

\section{PERNIKAHAN SECARA ATAS TALIAN}

Seperti yang telah diketahui, perkembangan teknologi telah mewujudkan pelbagai perkara baru yang memerlukan penelitian dari sudut syarak sama ada ia dibenarkan ataupun tidak. Ini kerana ia merupakan suruhan dalam syariat Islam sendiri untuk memastikan hala tuju kehidupan manusia tidak lari daripada tujuan asal mereka iaitu beribadah kepada Allah SWT. Firman Allah SWT:

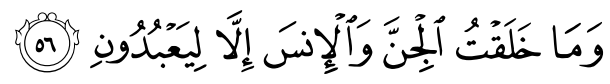

"Dan (ingatlah) Aku tidak menciptakan jin dan manusia melainkan untuk mereka menyembah dan beribadat kepadaKu."

(Surah al-Dhāriyāt, 51: 56)

Pernikahan secara atas talian merupakan salah satu daripada kesan interaksi antara teknologi dan syariat Islam yang memerlukan kepada penelitian dari sudut syarak. Ini kerana ia merupakan

$8 \quad$ Hadis riwayat 'Abdullah bin Mas'ūd dalam Sunan al-Nasā'̄i (2562). Lihat Imam Abū 'Abd al-Raḥmān Aḥmad Bin Syu'ayb Al-Nasā'̄̄, Al-Sunan al-Kubrā. Ed. Hasan 'Abd al-Mun'im. Cetakan Pertama. (Beirūt: Mu'assasah al-Risālah,2001),Jilid. 3, 139. Juga diriwayatkan oleh Bukhāri (1905), Muslim (1400), Abū Dāwūd (2046), Ibn Mājah (1845) dan Tirmizi (1081).

9 Al-Zuhaylī, Wahbah, al-Fiqh al-Islāmī wa Adillatuh, 36. 
perkara yang belum pernah berlaku pada zaman dahulu dan sudah tentu tidak dibahaskan oleh para fuqaha silam dengan terperinci mengenainya. Selain itu, Islam juga meletakkan prinsip yang ketat dalam melangsungkan perkahwinan iaitu berdasarkan kaedah alașl fì al-abḍa 'al-tahrìm (pada asalnya persetubuhan adalah haram sehingga ada perkara yang mengharuskannya) di mana aplikasi kaedah ini menatijahkan apabila bertembungnya hukum halal dan haram bagi menentukan hukum sesuatu perkahwinan, hukum haram adalah lebih patut diambil. ${ }^{10}$

Berbeza dengan perkara-perkara lain seperti muamalat dan pemakanan yang lebih longgar dari segi prinsipnya iaitu berdasarkan kaedah al-așl fì al-asyya ' al-ibāhah yang bermaksud pada asalnya sesuatu perkara itu harus sehingga ada dalil yang mengharamkannya. ${ }^{11} \mathrm{Hal}$ ini demikian, Islam begitu menjaga dan meninggikan kehormatan manusia untuk mengelakkan sebarang kemungkinan yang akan menyebabkan mereka melakukan perzinaan kerana hasil daripada perzinaan akan menyebabkan maqāșid al-syarī'ah tidak dapat direalisasikan akibat kerosakan dalam institusi keluarga dan masyarakat. Bahkan Allah SWT sendiri mengharamkan manusia daripada perbuatan mendekati zina, maka hukum haram tersebut adalah lebih berat pada perbuatan berzina itu sendiri.

Melihat kepada akad nikah melalui internet, ia boleh dilaksanakan dengan jarak jauh tanpa kedua-dua pihak iaitu wali dan pasangan lelaki perlu untuk hadir bertemu dalam satu tempat atau majlis. Pernikahan secara atas talian boleh dibahagikan kepada tiga kaedah, ${ }^{12}$ iaitu:

\section{Pernikahan Melalui Mesej}

Pernikahan secara atas talian melalui mesej boleh berlaku melalui

10 Jalāl al-Dīn 'Abd al-Rahmān al-Suyūṭ̂, al-Asybāh wa al-Naẓā'ir F̄̄ Qawā'id wa Furū' Fiqh al-Syāfi 'iyyah, Cetakan Pertama (Bayrūt: Dār al-Kutub al-'Ilmiyyah, 1983), 61.

11 Ibid., 60. Ini merupakan kaedah yang digunakan oleh jumhur fuqaha. Adapun fuqaha Hanafiyah sebaliknya menggunakan kaedah al-aṣl fi al-asyyā'al-tahrìm.

12 Kamaruddin, M.A. "Marriage Contact Using The Internet," (2018), 228. 
pelbagai medium iaitu antaranya ialah melalui aplikasi Facebook Messenger, Whatsapp, Telegram, WeChat dan sebagainya. Keduadua belah pihak yang berakad mestilah boleh berhubung melalui aplikasi-aplikasi yang digunakan dan mempunyai rangkaian internet yang laju untuk membolehkan mereka berkomunikasi antara satu sama lain dengan lancar. Akad nikah boleh berlaku dalam dua cara iaitu pertama; wali menghantar mesej lafaz $\bar{i} j \bar{a} b$ kepada pasangan lelaki, dan pasangan lelaki akan membalas dengan mesej lafaz qabūl sambil disaksikan oleh dua orang saksi. Kedua; akad nikah dilaksanakan dalam suatu forum maya atau kumpulan yang disertai oleh kedua-dua pihak yang berakad dan dua orang saksi untuk menyaksikan lafaz $\bar{j} \bar{a} b$ dan qabūl tersebut melalui mesej yang dihantar. Melalui kaedah ini, kedua-dua pihak yang berakad dapat berhubung secara langsung tetapi saling tidak dapat melihat rupa fizikal dan mendengar suara antara mereka kerana akad hanya berlangsung secara bertulis tanpa ada suara dan video.

\section{Pernikahan Melalui Panggilan Suara}

Pernikahan melalui cara ini boleh berlansung melalui beberapa medium sama ada melalui panggilan nombor talian pengguna (phone call), ataupun melalui medium Facebook Messenger, Whatsapp, Telegram, WeChat, Skype, Google Voice dan lain-lain. Kedua-dua belah pihak juga mestilah boleh berhubung dengan aplikasi-aplikasi yang digunakan dan mempunyai rangkaian internet yang laju untuk melancarkan proses akad nikah. Pernikahan berlansung dengan cara wali tersebut mengungkapkan lafaz $\bar{l} j \bar{a} b$ yang dapat didengari oleh pasangan lelaki dan pasangan lelaki tersebut melafazkan qabūl sambil didengari oleh dua orang saksi, ataupun kesemua pihak berada dalam satu forum maya atau kumpulan dan melangsungkan akad nikah dalam forum tersebut. Perbezaan medium pernikahan ini dengan akad nikah biasa adalah semua pihak yang terlibat iaitu kedua-dua belah pihak yang berakad dan dua orang saksi tidak dapat melihat rupa fizikal masing-masing ketika akad tersebut berlansung dan kedua-dua belah pihak yang berakad tidak berada dalam satu tempat. 


\section{Pernikahan Melalui Sidang Video}

Pernikahan melalui cara ini adalah yang paling mirip dengan pernikahan biasa di mana kesemua pihak yang terlibat boleh mendengar suara dan melihat rupa fizikal masing-masing ketika melangsungkan akad tersebut, cuma mereka juga tidak berada dalam satu tempat. Ia boleh berlansung melalui pelbagai aplikasi, antaranya ialah Facebook Messenger, Whatsapp, Google Meet, Zoom, Skype dan lain-lain aplikasi.

Berdasarkan kaedah-kaedah pernikahan atas talian yang telah disenaraikan, terdapat beberapa kelemahan yang dapat dikenalpasti. ${ }^{13}$ Antaranya adalah ia terdedah kepada unsur penipuan dan bermain-main dengan akad nikah. Terutamanya bagi pernikahan melalui mesej yang mungkin boleh berlaku penyamaran individu kerana tidak ada suara ataupun video yang boleh mengesahkan secara pasti identiti kedua-dua belah pihak. Bagi pernikahan panggilan suara dan sidang video pula, penipuan boleh berlaku dengan cara memanipulasikan suara dan video untuk menyerupai orang lain dan ini boleh dilakukan dengan pelbagai aplikasi yang terdapat sama ada dalam telefon atau komputer. Selain itu, boleh berlaku masalah luaran yang menyebabkan terganggunya proses perlangsungan akad nikah seperti kelambatan atau terputusnya rangkaian internet ataupun alat komunikasi yang digunakan seperti telefon dan komputer mengalami gangguan atau kerosakan. Perkara ini akan menyebabkan ungkapan $\bar{j} j \bar{a} b$ dan qabül tidak dapat berjalan secara lancar atau terpisah dan akan membatalkan akad tersebut.

\section{PANDANGAN FUQAHA MUTAQADDIMĪN}

Fuqaha daripada kalangan mutaqaddimin tidak pernah membahaskan mengenai pernikahan secara atas talian dengan terperinci, namun ia masih boleh dikaitkan dengan beberapa perbahasan mereka yang sedia ada mengenai akad nikah iaitu pada perbahasan mengenai ungkapan $\bar{j} \bar{a} b$ dan qabūl, ittiḥ̂ad almajlis (berada dalam satu majlis) dan penyaksian oleh orang buta dan pekak.

13 Kamaruddin, M.A., "Marriage Contact Using The Internet," (2018), $241-250$. 


\section{Ijāa dan Qabūl}

Dalam rukun nikah, para fuqaha bersepakat bahawa $\bar{\jmath} j \bar{a} b$ dan qabu $\bar{l}$ merupakan sebahagian daripada rukun nikah. ${ }^{14}$ Fuqaha Ḥanafiyah mengatakan bahawa rukun nikah hanyalah $\bar{j} j \bar{a} b$ dan qabūl tanpa menambah apa-apa rukun lain. ${ }^{15}$ Secara asasnya, $\bar{j} j \bar{a} b$ dan qabūl boleh berlaku dalam tiga bentuk iaitu ucapan, tulisan dan juga isyarat. Fuqaha bersepakat bahawa lafaz $\bar{j} \bar{a} b$ dan qabūl dalam nikah dikira sah dan terlaksana secara lafaz dengan perkataan inkāh (pernikahan) dan tazwīj (perkahwinan). ${ }^{16}$ Mengenai ungkapan secara tulisan dan isyarat pula, terdapat perbahasan yang berlaku antara para fuqaha, iaitu sama ada mereka berada dalam satu majlis atau tidak. Dalam keadaan mereka bersama dalam satu majlis, tiada khilaf antara fuqaha bahawa kaedah tulisan dan isyarat tidak boleh digunakan dalam melafazkan akad nikah walaupun tulisan dan isyarat tersebut jelas menunjukkan persetujuan dalam akad nikah. Hal ini demikian, kedua-dua pihak berkemampuan untuk bertutur menggunakan lidah serta tiada keperluan mendesak (darurat) dalam menggunakan kaedah tulisan

14 Muhammad Abū Zuhrah, Al-Aḥwāl al-Syakhșiyah. Cetakan Ketiga. T.tp. (Dār al-Fikr al-'Arabī, 1958), 40.

15 'Alā' al-Dīn Abī Bakr Bin Mas'ūd Al-Kasān̄̄ (2003). Badā'i' alSanā' $i$ ' Fì Tartīb al-Syarā'i'. Eds. Syeikh 'Alī Muḥammad dan Syeikh 'Ādil Aḥmad. Cetakan Kedua. (Beirūt: Dār al-Kutub al'Ilmiyyah, 2003), Jilid 3, 317.

16 Rujukan Mazhab Hanafĩ: 'Alā' al-Dīn Abī Bakr Bin Mas'ūd AlKasānī (2003). Badā'i ‘ al-Sanā'i ‘ Fì Tartīb al-Syarā' $i$ ', (2003), Jilid 3, 317; rujukan Mazhab Mālikī: Muḥammad Bin Muḥammad Bin 'Abd al-Raḥman Muḥammad Bin Muḥammad Bin 'Abd al-Rạ̣man Al-Haț̣ābī, Mawāhib al-Jalīl Li Syarh Mukhtașar Khalīl. Ed. Zakariyā 'Amīrāt (Bayrūt: Dār 'Ālim al-Kutub, 2003), 5: 43; rujukan Mazhab Syāfi‘ī: Syams al-Dīn Bin Muḥammad Bin Muḥammad al-Khațīb al-Syarbīn̄i, al-Iqnā' F̄̄ Hilli Alfāz Abì Syujā'. Eds, 'Alī Muḥammad Mu'awwaḍ dan 'Ādil Aḥmad 'Abd al-Mawjūd. Cetakan Ketiga (Bayrūt: Dār al-Kutub al-'Ilmiyyah, 2003), 2: 245; rujukan Mazhab Hanbalī: Mansur Bin Yūnus Bin Idrīs al-Bahūt̄̄, Syarḥ Muntahā al-Irādāt al-Musammā Daqā'iq Ūlì al-Nuhā Li Syarh Muntahā. Cetakan Pertama (Bayrūt: 'Ālam al-Kutub 1993), 2: 631. 
dan isyarat. ${ }^{17}$ Lebih-lebih lagi ungkapan $\bar{j} j \bar{a} b$ dan qabūl secara lafaz lebih kuat dan jelas dari segi maknanya berbanding tulisan dan isyarat. Walau bagaimanapun, fuqaha bersepakat bahawa terdapat pengecualian yang diberikan kepada orang yang bisu iaitu mereka boleh mengungkapkan $\bar{j} j \bar{a} b$ dan qabūl secara tulisan dan isyarat kerana ia dianggap darurat. Namun begitu, ungkapan $\bar{\jmath} j a \bar{a} b$ dan qabūl adalah lebih afdal dilakukan secara tulisan kerana ia dianggap lebih jelas daripada isyarat. ${ }^{18}$

Dalam keadaan mereka tidak berada dalam satu majlis pula iaitu salah satu daripada pihak yang berakad tidak dapat menghadirkan diri, jumhur fuqaha mengatakan bahawa ianya tidak sah untuk melakukan akad secara bertulis atau mengutus surat kerana tulisan dianggap kināyah (kiasan) yang memerlukan kepada penjelasan maksud sebenar oleh pengucapnya manakala sebahagian fuqaha Hanafiyah seperti Abū Yūsuf ${ }^{19}$ dan Ibn 'Ābidīn ${ }^{20}$ mengatakan bahawa ianya sah kerana apabila satu pihak itu mengutuskan surat lafaz $\bar{l} j \bar{a} b$ kepada pihak yang lain, lalu pengutus tersebut membacakan akad $\bar{l} j \bar{a} b$ tersebut dan pihak yang lain menerima dengan lafaz qabūl sambil didengari dan disaksikan oleh dua

17 Rujukan Mazhab Ḥanafì: Zayn al-Dīn Bin Ibrāhīm Bin Muḥammad Ibn Nujaym, Al-Bahrr al-Rā'iq Syarh Kannz al-Daqā'iq. Cetakan Kedua (Qāhirah: Dār al-Kitāb al-Islāmī, t.t.), 3: 90; rujukan Mazhab Mālikī: Abū al-'Abbās Ahmmad Bin Muḥammad al-Șāwī , Bulghah al-Sālik li Aqrab al-Masālik (Hāsyiah al-S̄āwō 'Alā Syarh al-Ṣaghīr. (t.t.p., Dār al-Ma'ārif, t.t.), 2: 350; Mazhab Syāfi'īi: Syams al-Dīn Bin Muḥammad Bin Muḥammad al-Khațīb al-Syarbīnī, Mughnī alMuḥtāj Ilā Ma 'rifah Ma 'ānī Alfäza al-Minhāj. Eds. 'Alī Muḥammad Mu'awwạ̣ dan 'Ādil Aḥmad 'Abd al-Mawjūd. (Beyrūt: Dār alKutub al-'Ilmiyyah, 2000), 4: 230; rujukan Mazhab Ḥanbalī: Mușțafā Bin Sa'd Bin 'Abduh al-Suyūṭi al-Rahīibānī (1994), Mațālib Ūlī al-Nuhā Fì Syarh Ghāyah al-Muntahā (Bayrūt: al-Maktab alIstāmī, 1994), 5: 50.

18 Muștafā Bin Sa'd Bin 'Abduh al-Suyūṭ̂̀ al-Rahịīānī, Mațālib Ūlī al-Nuhā F̄̄ Syarh Ghāyah al-Muntahā. (1994), 5: 50.

19 'Alā' al-Dīn Abī Bakr Bin Mas' ūd Al-Kasān̄̄, Badā'i ' al-Sanā 'i ' fì Tartīb al-Syarā'i' '.(2003), 3: 326.

20 Muhammad Amīn Ibn 'Ābidīn, Radd al-Mukhtār 'Alā al-Durr alMukhtār Syarh Tanwīr al-Abșār. Eds. Syeikh 'Ādil Aḥmad 'Abdul Mawjūd dan Syeikh 'Alī Muhammad Mu'awwaḍ (Riyāḍ: Dār 'Ālim al-Kutub, 2003), 4: 73-74. 
orang saksi, ia dikira sebagai berada di dalam satu majlis dari sudut makna kerana ucapan daripada pihak pengutus merupakan ucapan daripada pihak yang mengutuskannya dan begitu juga tulisan dalam surat dianggap daripada pengutusnya juga. Kaedah oleh fuqaha Hanafiyah menganggap bahawa tulisan atau surat daripada orang yang tidak dapat hadir adalah sama keadaannya seperti kata-kata orang yang hadir. ${ }^{21}$

\section{Ittihāa d al-Majlis}

Dari sudut ittiḩād al-majlis (berada bersama dalam satu majlis) atau ittiḩād al-zamān (berada bersama dalam satu masa), terdapat perbahasan di kalangan fuqaha mengenai perkara ini. Fuqaha Hanafiyah mengatakan bahawa syarat bagi $\bar{j} j \bar{a} b$ dan qabūl ialah ittiḥād al-majlis dan ittiḥ̂ad al-zamānn. ${ }^{22}$ Oleh itu, sekiranya seseorang melafazkan $\bar{j} \bar{a} b$ dan pihak yang lain meninggalkan majlis tersebut, maka ia dikira terbatal. Walau bagaimanapun, tidak disyaratkan bersegera tetapi mestilah jarak masa antara $\bar{i} \bar{a} b$ dan qabūl itu tidak terlalu panjang. ${ }^{23}$ Fuqaha Mālikiyah pula berpandangan bahawa perlu bersegara untuk melafazkan qabūl dan masih sah akad nikah sekiranya ìjāb dan qabūl terpisah dalam jangka masa pendek. ${ }^{24}$ Fuqaha Syāfi'iyyah pula berpendapat bahawa disyaratkan bersegera antara $\bar{i} j \bar{a} b$ dan qabūl dalam majlis tersebut dan tidak sah akad nikah sekiranya jarak

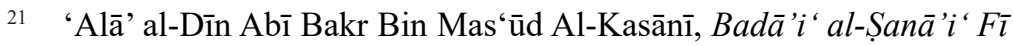
Tartīb al-Syarā' 'i' . (2003)Jilid. 3, 326.

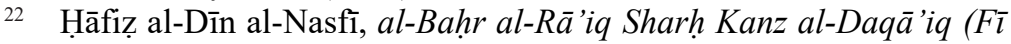
Furū' al-Hanafiyah). Cetakan Pertama (Bayrūt: Dār al-Kutub al'Ilmiyyah, 1993). Jilid. 3, 148. Lihat juga Muhammad Amīn Ibn 'Ābidīn, Radd al-Mukhtār 'Alā al-Durr al-Mukhtār Syarh Tanwīr al-Abșār. (2003), Jilid. 4, 70.

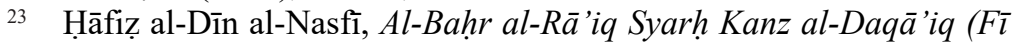
Furū'al-Hanafiyah). (1997), Jilid. Ketiga, 148.

24 Abū 'Abdullāh Muhammad Bin Muhammad Bin 'Abd al-Rahmman Al-Ḥațāāi Mawāhib al-Jalīl Li Syarh Mukhtașar Khalīl. (Beirūt: Dār al-Kutub al-'Ilmiyyah,2003). Jilid Kelima, , 47. 
masa antara keduanya panjang. ${ }^{25}$ Manakala Fuqaha Hanābilah mengatakan bahawa sekiranya lafaz qabūl dilewatkan daripada lafaz $\bar{j} \bar{a} b$ sehingga terpisahnya majlis, ataupun kedua-dua pihak menyibukkan diri dengan perkara lain yang memisahkan kedua lafaz tersebut secara uruf yang akan menyebabkan akad tersebut terbatal. ${ }^{26}$ Oleh itu, boleh dikatakan bahawa para fuqaha bersepakat dalam menentukan ittihâ̄d al-majlis sebagai syarat nikah, meskipun mereka perbeza pendapat dalam menyentuh perkara furū' seperti jarak masa antara lafaz $\bar{l} j a \bar{a} b$ dan qabūl.

\section{Saksi Buta dan Pekak}

Jumhur fuqaha menyatakan bahawa saksi merupakan syarat bagi nikah $^{27}$ sementara fuqaha Shāfi'iyyah berpendapat bahawa ia adalah rukun. ${ }^{28}$ Ini adalah berdasarkan hadis:

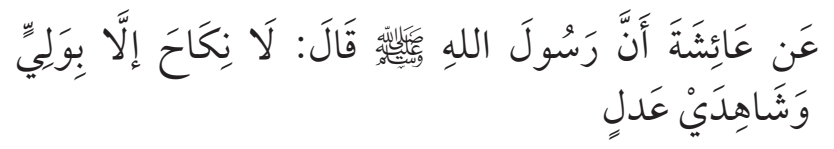

"Daripada 'Á'isyah RA bahawa Rasulullah SAW telah bersabda: Tiada pernikahan kecuali dengan

25 Muhy Al-Dīn Abī Zakariyyā Bin Syaraf Al-Nawawī. Rawḍh alȚālibīn Wa 'Umdah al-Muftīn. Cetakan Ketiga. (Beirūt: Al-Maktab al-Islāmī, 1991). Jilid. Ketujuh, 37-38. Lihat juga Jalāl al-Dīn Muḥammad Bin Aḥmad Bin Muḥammad Al-Maḥallī (2013). Kanz al-Rāghibīn Syarh Minhāj al-Ṭālibīn. Cetakan Kedua. (Jeddah: Dār al-Minhāj,2013). Jilid Kedua, 209-210.

26 Mansur Bin Yūnus Bin Idrīs Al-Bahūt̄̄ (1993). Syarh Muntahā al-Irādāt al-Musammā Daqā'iq Ūlī al-Nuhā Li Syarh Muntahā., (1993), Jilid. Kedua, 633.

27 Abū al-Walīd Muhammad Bin Aḥmad Bin Muḥammad Bin Rusyd, Bidāyah al-Mujtahid wa Nihāyah al-Muqtașid. Ed. Muḥammad Subḥ̄ Hasan Halāq. Cetakan Pertama. (Qāhirah: Maktabah Ibn Taymiyyah,1995), Jilid Ketiga, , 35.

28 Muhy Al-Dīn Ab̄̄ Zakariyyā Bin Syaraf Al-Nawawī, Rawdah alTâalibīn (1991). Jilid. Ketujuh, , 45. 
wali dan dua orang saksi yang adil." 29

Bagi syarat kebolehan saksi untuk melihat, fuqaha Syāfi'iyyah menetapkan bahawa saksi mestilah boleh melihat dan mendengar untuk mengesahkan akad nikah tersebut berdasarkan pendapat yang paling kuat dalam mazhab ini. ${ }^{30}$

Sementara jumhur termasuk pendapat yang lain dalam mazhab Syāfi' $1 \overline{\text { b }}$ berpendapat tidak mengapa sekiranya saksi tersebut buta asalkan boleh mengenalpasti dan membezakan suara orang yang berakad dengan suara orang lain. ${ }^{31}$ Oleh yang demikian, akad nikah tidak sah sekiranya saksi merupakan orang yang tidur, pekak dan mabuk di sisi jumhur ${ }^{32}$ dan fuqaha Syāfi'iyyah menambah lagi iaitu tidak sah juga penyaksian orang yang buta dalam akad nikah. ${ }^{33}$ Disyaratkan juga untuk saksi yang mendengar akad nikah berkebolehan untuk memahami ucapan kedua-dua pihak yang berakad kerana tujuan disyariatkan penyaksian dalam akad nikah tidak akan tercapai sekiranya mereka sendiri tidak memahami lafaz akad nikah yang diungkapkan. ${ }^{34}$

\section{KESIMPULAN PANDANGAN FUQAHA MUTAQADDIMĪN TERHADAP HUKUM AKAD NIKAH SECARA ATAS TALIAN}

Berdasarkan perbahasan-perbahasan daripada fuqaha mutaqaddimin yang telah dibincangkan, boleh dikatakan bahawa

29 Hadis riwayat Ibn Ḥibbān (4080). Lihat 'Alā' al-Dīn Bin Balbān alFārisī, al-Iḥsān fì Taqrīb Sạhịh Ibn Hibbān. Ed Markaz al-Buhūth Wa Taqniyah al-Ma'lūmāt. Cetaka Pertama (Bayrūt: Dār al-Ta'ṣîl, 2014) Jilid Kelima, 89.

30 Muhy Al-Dīn Abī Zakariyyā Bin Syaraf Al-Nawawī, Rawdah alṬālibìn.(1991) Jilid. Ketujuh, 45. Lihat juga Jalāl al-Dīn Muḥammad Bin Aḥmad Bin Muḥammad Al-Maḥallī, Kanz al-Rāghibīn. (2013), Jilid. Kedua, , 212.

31 Al-Zuhaylī, Wahbah, al-Fiqh al-Islāmī wa Adillatuh. (1985), Jilid. 7, 76.

32 Ibid., 76-77.

33 Al-Zuhaylī, Muhammad, al-Mu 'tamad fì al-Fiqh al-Shāfi 'ì. Cetakan Ketiga. (Damsyiq: Dār al-Qalam, 2011), Jilid. Keempat, 69.

34 Al-Zuhaylī, Wahbah, al-Fiqh al-Islāmī wa Adillatuh (1985), Jilid. 7, 77. 
jumhur fuqaha dari kalangan Mālikiyah, Syāfi'iyyah dan Hanābilah menolak keharusan bernikah secara mesej sementara fuqaha Hanafiyah mengharuskannya. Hujah bagi pendapat jumhur adalah tidak sah akad nikah secara mesej kerana lafaz $\bar{i} j \bar{a} b$ dan qabül secara bertulis adalah kināyah yang memerlukan kepada penjelasan maksud sebenar oleh pengucapnya. Selain itu, pernikahan secara bertulis juga tidak membolehkan saksi untuk mendengar ungkapan șighah $\bar{\imath} \bar{a} b$ dan qabül yang merupakan syarat sah akad nikah kerana mesej tidak mengandungi bunyi atau suara yang membolehkan kedua-dua pihak mendengar antara satu sama lain.

Di sisi fuqaha Hanafiyah pula, pernikahan secara atas talian melalui mesej adalah sah sekiranya akad nikah tersebut berlansung dalam keadaan kedua-dua pihak tidak dapat hadir dalam satu majlis dan pihak yang berakad menggunakan medium mesej sebagai perantaraan, dengan syarat, mesej lafaz ija $\bar{a} b$ tersebut perlulah dibaca dan didengar oleh dua orang saksi dan begitu juga syaratnya dengan lafaz qabūl. Dari aspek ittiḥ̂ad almajlis pula, lafaz akad nikah melalui mesej dianggap bertepatan dan tidak bercanggah dengan aspek ini kerana kaedah fuqaha Hanafiyah yang menyebutkan bahawa tulisan orang yang tidak hadir dianggap sama seperti kata-kata orang yang hadir.

Seperti yang telah disebutkan sebelum ini bahawa pernikahan secara mesej boleh berlaku dalam dua cara, iaitu sama ada kedua-dua pihak berhubung secara langsung melalui mesej dan disaksikan oleh dua orang saksi, ataupun mereka berkumpul bersama dua orang saksi dalam satu forum maya atau kumpulan sebagai medium untuk melafazkan akad. Oleh itu, akad nikah hanya sah pada cara yang pertama kerana saksi masih boleh mendengar lafaz $\bar{j} j \bar{a} b$ dan qabül oleh pihak yang berakad kerana ia dibacakan di hadapan mereka, sementara cara yang kedua pula tidak sah kerana saksi tidak dapat mendengar șighah ìjāb dan qabūl ketika ia diungkapkan kerana mereka tidak berada pada satu tempat untuk mendengar suara pihak yang berakad.

Berkenaan pernikahan secara panggilan suara dan sidang video pula, tidak dapat disimpulkan secara jelas pandangan fuqaha mutaqaddimīn mengenai perkara ini kerana tidak dijumpai perbahasan yang menghuraikan dengan tuntas mengenai apakah 
yang dimaksudkan dengan ittiḩād al-majlis. Adakah ia bermaksud kedua-dua pihak yang berakad dan juga dua orang saksi mesti berada bersama secara fizikal iaitu berada dalam satu tempat ataupun memadai berada bersama dalam satu masa sahaja? Walaubagaimanapun, boleh dikatakan bahawa fuqaha Hanafiyah mengharuskan juga akad nikah secara panggilan suara dan sidang video jika dikiaskan hukumnya daripada pernikahan secara bertulis bagi yang tidak dapat hadir dalam satu majlis kerana terdapat 'illah yang sama iaitu kedua-dua keadaan membolehkan pihak masing-masing untuk melafazkan $\bar{\imath} j a \bar{a} b$ dan qabül, tambahan lagi kedudukannya yang lebih jelas dari aspek pelaksanaan dan perlangsungannya berbanding pernikahan secara bertulis.

\section{PANDANGAN FUQAHA MUTA'AKHKHIRĪN}

Dalam kalangan fuqaha muta'akhkhirīn, antara yang menerima pelaksanaan akad nikah secara atas talian ialah Ibrāhīm Fāḍil al-Dabw ${ }^{35}$, al-Zuḥaylīin, Muștafā al-Zarqā̄ ${ }^{37}$, Badrān Abū al'Aynayn ${ }^{38}$, Muḥammad 'Uqlah al-Ibrāhīm, ${ }^{39}$ Usāmah 'Umar Sulaymān al-Asyqar ${ }^{40}$, 'Abd al-Ilāh bin Mazrū' al-Mazrū', ${ }^{41}$ Muḥammad bin Yaḥyā al-Najīmīi, ${ }^{42}$ 'Abd al-'Azīz Syākir Ḥamdān

35 Ibrāhīm Fāọil al-Dabw, "Ḥukm Ijrā’ al-'Uqūd Bi Ālāt al-Ittișāl alHadīthah", Majallah Majma " al-Fiqh al-Islāmī, (t.t.) No 6, 56.

36 Wahbah Muștafāa al-Zuḥaylī, "Hukm Ijrā' al-'Uqūd Bi Ālāt al-Ittișāl al-Hadīthah", Majallah Majma “al-Fiqh al-Islāmī, (t.t.), No 6, , 655.

37 Muhammad 'Uqlah, "Hukm Ijrā' al-'Uqūd 'Abr Wasā'il al-Ittișāl,", Majallah al-Syarī'ah, no. 5 (1986) 135.

38 Ibid.

39 Ibid.

40 Usāmah 'Umar Sulaymān al-Asyqar, Mustajiddāt Fiqhiyyah fì Qaḍāyā al-Ziwāj wa al-Talāq (Jordan: Dār al-Nafâ'is, 2000), 111.

${ }^{41}$ 'Abd al-Ilāh bin Mazrū' al-Mazrū', 'Aqd al-Ziwāj 'Abr al-Intarnit (t.t.p.: t.p., t.t.), 22.

42 Muhammad Ibn Yahyāa al-Najīmī, Hukm Ibrām 'Uqūd al-Ahwāl alSyakhșiyyah Wa al- 'Uqūd al-Tijāriyyah 'Abr Wasā'il al-Iliktrūniyah (t.t.p.: t.p., t.t.), 13, 16 dan 17. 
al-Kubaysīi, ${ }^{43}$ Muḥammad Khalaf Muḥammad Banī Salāmah ${ }^{44}$ dan Syeikh 'Abd al-'Azīz Bin Bāz. ${ }^{45}$ Secara jelasnya, semua fuqaha yang mengharuskan pernikahan secara atas talian mensyaratkan wajib adanya saksi bagi akad nikah tersebut.

Meskipun kebanyakan daripada fuqaha yang disebutkan tidak menyatakan secara jelas mengenai keharusan akad nikah melalui kaedah sidang video, namun persetujuan mereka dalam mengharuskan akad nikah melalui panggilan suara dan mesej menandakan penerimaan mereka secara jelas terhadap kaedah ini. 'Umar Sulaymān al-Asyqar dalam karangan beliau Mustajiddāt Fiqhiyyah Fì Qa dāaya al-Ziwāj wa al-Talāq menyebutkan bahawa akad nikah secara atas talian memenuhi kesemua tuntutan rukun dan syarat dari segi lafaz $\bar{j} \bar{a} b$ dan qabūl serta penyaksian oleh dua orang saksi ${ }^{46}$, bahkan terdapat asas dalam perbahasan fuqaha mutaqaddiminn mengenai pernikahan dengan cara ini iaitu seperti yang disebutkan oleh al-Nawawī dalam al-Majmū' di mana sah akad antara dua pihak yang boleh mendengar antara satu sama lain, tidak kira sama ada mereka berada di satu tempat atau tidak, dan begitu juga tidak kira sama ada mereka dapat melihat satu sama lain atau tidak. ${ }^{47}$

Oleh kerana al-Nawawī mengharuskan akad dalam keadaan kedua-dua pihak mungkin tidak melihat satu sama lain, pendapat ini menjadi perintis kepada ijtihad fuqaha muta'akhkhirin dalam mengharuskan akad nikah secara atas talian yang mana pelaksanaannya lebih jelas daripada yang digambarkan oleh

43 'Abd al-'Azīz Syākir Ḥamdān, Ḥukm 'Aqd al-Ziwāj bi Wasīṭah al-Taqniyyāt al-Mu'āṣarah: Wasā'il al-Ittișāl al-Masmū'ah wa alMar'iyyah Anmūdhjan. Kertas kerja dibentangkan dalam Seminar alAnkiḥah al-Mustaḥdathah fĩ Wāqi'ina al-Mu'āṣir, Jabatan Pengajian Syariah dan Islam, University of the United Arab Emirates, 28 April 2015.

44 Muḥammad Khalaf Muḥammad Ban̄̄ Salāmah, "Masyrū'iyyah 'Uqūd al-Ziwāj Bi al-Kitābah 'Abr al-Internet”. Majallah al-Jāmi 'ah al-Islāmiyyah li al-Dirāsāt al-Islāmiyyah 12, no. 2 (2014), 533.

45 https://islamqa.info/ar/answers/2201/ diakses pada 1 Jun 2021

46 Usāmah 'Umar Sulaymān al-Asyqar, Mustajiddāt Fiqhiyyah fì Qaụāyā al-Ziwāj wa al-Talāq (2000), 108-109.

47 Muḥy al-Dīn Ab̄̄ Zakariyyā Bin Sharf al-Nawawīe al-Majmū ' Sharḥ al-Muhadhdhab. Madīnah: al-Maktabah al-Salafiyyah, t.t.), 9: 181. 
ulama terdahulu, yakni kedua-dua pihak dapat berkomunikasi secara langsung sama ada melalui mesej, panggilan suara, dan lebih-lebih lagi sidang video.

Pendapat ini dikukuhkan lagi dengan asas bahawa terdapat perbincangan dalam kalangan fuqaha mutaqaddimin yang membenarkan penyaksian orang yang buta yang masih boleh mendengar suara pihak yang berakad. Daripada asas ini, mereka membina hujah dengan menyatakan bahawa saksi bagi akad nikah boleh mendengar lafaz $\bar{j} \bar{a} b$ dan qabūl daripada kedua-dua belah pihak yang menjadikan akad tersebut seakan-akan mereka berada bersama dalam satu majlis. ${ }^{48}$

'Abd al-Ilāh bin Mazrū' al-Mazrū' telah menyebutkan bahawa hendaklah dipastikan bahawa tiada unsur main-main dan tipu helah dalam melakukan akad nikah dengan kaedah ini. ${ }^{49}$ Walaubagaiamanapun, beliau juga menyebutkan bahawa kaedah ini bukanlah dibenarkan secara mutlak, tetapi ia harus dilaksanakan atas dasar darurat seperti keadaan yang menyukarkan kedua-dua pihak untuk berada bersama dalam satu majlis. ${ }^{50}$ Selain itu, al-Zuḥaylī dan Ibrāhīm Fāḍil al-Dabw juga berhujah bahawa konsep ittiḥ̂ad al-majlis bukanlah bermaksud kesemua pihak yang berakad perlu berada dalam tempat yang sama, akan tetapi cukup sekadar mereka berada dalam masa yang sama. ${ }^{51}$ Berkenaan kaedah fiqh yuhtāt fì al-furūj mā là yuhtāt fì ghayrihāa, ia bukannya menjadi penghalang bagi pelaksanaannya, bahkan ia menjadi syarat pelaksanaan untuk memastikan akad tersebut benar-benar dilaksanakan dalam keadaan selamat daripada penipuan dan penyelewengan. ${ }^{52}$

Walaupun begitu, 'Umar Sulaymān al-Asyqār menyebutkan bahawa kebanyakan fuqaha tidak mengharuskan pernikahan

48 Kamaruddin, M.A., "Marriage Contact Using The Internet” (2018), 248-249.

49 'Abd al-Ilāh bin Mazrū' al-Mazrū', 'Aqd al-Ziwāj 'Abr al-Intarnit. t.tp.: t.p., 21.

50 Ibid.

51 Wahbah Mușțafā al-Zuhaylī dan Ibrāhīm Fāḍil al-Dabw, "Hukm Ijrā' al-'Uqūd Bi Ālāt al-Ittișāl al-Hadīthah", Majallah Majma' alFiqh al-Islāmī, No 6, 655 dan 668.

52 Usāmah 'Umar Sulaymān al-Asyqar, Mustajiddāt Fiqhiyyah F̄̄ Qậāyā al-Ziwāj wa al-Ṭalāq, (2000) 111. 
secara atas talian. Antara yang disebutkan oleh beliau adalah fuqaha daripada kalangan al-Lajnah al-Dā'imah li al-Buhūth al'Ilmiyyah wa al-Iftā' di Arab Saudi dan Majma' al-Fiqh al-Islāmī di Jeddah. ${ }^{53}$ Pihak al-Lajnah al-Dā'imah li al-Buhūth al-'Ilmiyyah wa al-Iftà' telah menegaskan pendapat mereka dengan hujah bahawa teknologi pada zaman sekarang boleh menyebabkan berlakunya penyelewengan dan penyamaran identiti. Seseorang itu boleh menyamar dengan mengubah suaranya menjadi mirip suara orang lain, dan tidak mustahil juga bahawa hanya seorang individu sahaja boleh menyamar menjadi beberapa individu yang lain dalam satu masa. ${ }^{54}$ Selain itu, akad nikah tidak boleh disahkan dengan semata-mata mendengar suara pihak-pihak yang berakad kerana suara boleh bercampur dan berubah, dan ini hanya mencapai tahap keyakinan secara zannī dan bukannya qaț 'i $\bar{\imath}$. Sebaliknya, akad yang berkaitan muamalat harta adalah diharuskan dengan beberapa syarat yang tertentu yang telah ditetapkan. Ini adalah berdasarkan kepada kaedah fiqh yuhtāt fi al-furūj mā la yuhtāt $f i$ al-amwāl (perlu lebih berhati-hati dalam perkara berkaitan kemaluan daripada perkara berkaitan harta).

Merujuk kepada fatwa oleh Majma' al-Fiqh al-Islāmī pula, mereka menyatakan bahawa hukum akad nikah dengan menggunakan alat komunikasi secara moden iaitu melalui mesej ataupun panggilan suara adalah tidak sah dengan berpegang kepada pendapat fuqaha Syāfi'iyyah mengenai syarat saksi iaitu saksi mestilah boleh melihat pelangsungan akad nikah. ${ }^{55}$ Walau bagaimanapun, Majma' al-Fiqh al-Islāmī memberikan kelonggaran dengan mengharuskan akad nikah secara atas talian dengan berpegang kepada pendapat fuqaha mazhab lain serta memenuhi kesemua rukun dan syarat nikah sekiranya terdapat keperluan, terutamanya dalam menghadapi pandemik Covid-19

$53 \quad$ Ibid., 110.

54 Al-Lajnah al-Dā'imah Li al-Buhūth al-'Ilmiyyah Wa al-Iftā', Fatāwā Al-Lajnah al-Dā'imah Li al-Buhūth al-'Ilmiyyah Wa alIftā'. Ed. Syeikh Aḥmad bin 'Abd al-Razzāq al-Duwaysy. (Riyāụ: Mu'assasah al-Amīrah, 2018), 9: 50.

55 Majma' al-Fiqh al-Islāmī al-Sa 'ūdī, Bil: 52 (3/6) [1], Hukm Ijrā' al'Uqūd bi Ālāt al-Ittișāl al-Hadìthah. 
dengan menambah syarat bahawa ia mestilah mendapat keizinan daripada pihak berkuasa. ${ }^{56}$

Merujuk kepada Dār al-Iftā' Mesir pula, mereka menolak keharusan melangsungkan akad nikah secara sidang video dengan hujah bahawa boleh berlaku percampuran dan pengubahan suara walaupun terdapat video yang terpapar, kerana ia sentiasa terdedah kepada penipuan. Selain itu, akad nikah yang berlangsung secara sidang video tidak sampai ke tahap al-qat ' $i$ atau al-yaqin tetapi hanya pada tahan al-zan sahaja. Tambahan lagi, dibimbangi akan berlaku pernikahan secara berleluasa oleh golongan ISIS dalam merekrut ahli baru dan memperkukuhkan kuasa mereka. ${ }^{57}$ Oleh itu, fatwa ini dilihat sebagai langkah mengekang peluasan kuasa ISIS sekali gus menjaga maqasid dalam pensyariatan perkahwinan.

Di Malaysia pula, Muzakarah Jawatankuasa Fatwa Majlis Kebangsaan Bagi Hal Ehwal Ugama Islam Malaysia Kali Ke-97 yang bersidang pada 15-17 Disember 2011 telah memutuskan bahawa hukum akad nikah melalui sidang video adalah harus dan memenuhi syarat ittihād al-majlis dan dikelaskan sebagai ittihạad al-majāzz tetapi mestilah mematuhi beberapa syarat-syarat tertentu iaitu majlis perlu berlangsung pada tahap al-yaqin dan bukan al-zan, tiada unsur penipuan (al-gharar) dan keraguan, cukup semua rukun dan syarat-syarat sah nikah menurut hukum syarak, digalakkan wali sendiri yang mengakad-nikahkan pasangan, terdapat halangan untuk melakukan akad nikah di tempat yang ditentukan kerana berjauhan dan sukar bagi keduadua belah pihak berada dalam satu majlis yang sama disebabkan sakit, banjir dan sebagainya dan tertakluk kepada semua peraturan dan undang-undang yang sedang berkuatkuasa. ${ }^{58}$ Keputusan ini diterima oleh Mesyuarat Jawatankuasa Fatwa Negeri Sembilan Bil 1/1433H yang bersidang pada 21 Mac 2012 dengan menyetujui

56 https://alwafd.news/ أخبار -و تقارير / 822251-الإفتاء_تحذر -من-زو اج_الفيديو di akses pada 15 Mac 2021

57 https://arabic.cnn.com/middleeast/2015/03/05/egypt-fatwa-videoconf-marriage

58 Jabatan Kemajuan Islam Malaysia, Isu-Isu Fatwa Munakahat Keputusan Muzakarah Jawatankuasa Fatwa Majlis Kebangsaan Bagi Hal Ehwal Ugama Islam Malaysia. Cetakan Pertama. (W.P Putrajaya: JAKIM, 2013), 12-13. 
semua syarat-syarat yang diputuskan. ${ }^{59}$ Begitu juga Mesyuarat Jawatankuasa Fatwa Negeri Selangor memutuskan bahawa hukum nikah melalui sidang video adalah harus dengan syaratsyarat yang sama kecuali tidak dinyatakan galakan supaya wali sendiri yang mengakad-nikahkan pasangan. ${ }^{60}$ Namun begitu, tiada sebarang fatwa yang dikeluarkan oleh badan fatwa tempatan terhadap hukum pernikahan secara atas talian melalui mesej atau panggilan suara. Oleh itu, hukum tersebut berbalik semula kepada pendapat fuqaha Syāfi'iyyah yang menjadi rujukan utama dalam undang-undang keluarga Islam di Malaysia ${ }^{61}$ iaitu kedua-dua cara tersebut tidak sah kerana pernikahan secara bertulis adalah kināyah sementara pernikahan secara panggilan suara pula tidak membolehkan saksi melihat akad nikah tersebut berlangsung sedangkan syarat saksi bagi nikah mestilah boleh melihat dan mendengar.

\section{KESIMPULAN}

Pada dasarnya fuqaha mutaqaddimin dalam kalangan jumhur fuqaha Māliki, Syāfi'i dan Ḥanbali menolak keharusan bernikah secara mesej atau kaedah-kaedah lain seperti panggilan suara dan sidang video atas alasan-alasan dan dalil-dalil yang dikemukakan, manakala fuqaha Hanafi berdasarkan qiyās atas perkahwinan melalui al-kitābah atau tulisan dan al-risālah, mengharuskan perkahwinan melalui hantaran mesej dengan mematuhi syaratsyarat yang ditetapkan. Walaubagaimanapun, perkahwinan yang dilakukan melalui panggilan suara dan sidang video pula tidak dapat disimpulkan secara jelas pandangan fuqaha mutaqaddimin mengenai perkara ini kerana tidak dijumpai perbahasan yang menghuraikan dengan tuntas mengenai apakah yang dimaksudkan dengan ittihâad al-majlis. Adakah ia bermaksud kedua-dua pihak yang berakad dan juga dua orang saksi mesti berada bersama secara

59 http://e-smaf.islam.gov.my/e-smaf/fatwa/fatwa/find/pr/12419 di akses pada 12 Disember 2020

60 Keputusan Mesyuarat Jawatankuasa Fatwa Negeri Selangor Bil. 1/2016, bersidang pada 19 Januari 2016.

61 Raihanah Hj Azahari, "Kedudukan Mazhab Syafi'i dalam UndangUndang Keluarga Islam: Satu Realiti," Jurnal Fiqh 4 (2007), 257258. 
fizikal iaitu berada dalam satu tempat ataupun memadai berada bersama dalam satu masa sahaja. Bagaimana pun sebilangan fuqaha mutaakhirin dengan mengambil kira konteks semasa dan perkembangan dalam dunia teknologi menerima pelaksanaan akad nikah secara atas talian, dengan syarat tiada unsur main-main dengan lafaz akad yang dilakukan, manakala sebilangan yang lain pula menolak keharusannya kerana mengambil pendekatan berhati-hati dalam urusan hukum pernikahan. Pada hakikatnya perkembangan teknologi memberikan banyak manfaat dalam mencukupkan dan mempermudahkan urusan dan kehidupan harian manusia di samping unsur-unsur yang memudaratkan. Oleh kerana itu, penulis cenderung kepada pandangan yang mengharuskan pernikahan secara atas talian dengan kaedah sidang video apabila terdapat darurat dan keperluan dengan memenuhi kesemua syarat dan rukun serta mencapai tahap yakin kerana ia merupakan kaedah yang paling tinggi tahap keyakinannya. Adapun berkenaan kaedah yuhtāt fi al-furūj mā là yuhtāt fì alamwāl, penulis bersetuju bahawa ia tidak bermaksud larangan daripada melakukan akad nikah secara atas talian, sebaliknya ia melazimkan pihak yang berakad supaya lebih berhati-hati dalam melaksanakannya.

\section{RUJUKAN}

'Abd al-'Azīz Syākir Ḥamdān, Ḥukm 'Aqd al-Ziwāj bi Wasīṭah al-Taqniyyāt al-Mu'āṣarah: Wasā'il al-Ittișāl al-Masmū'ah wa al-Mar'iyyah Anmūdhjan. Kertas kerja dibentangkan dalam Seminar al-Ankiḥah al-Mustaḥdathah Fī Wāqi'ina al-Mu'āșir, Jabatan Pengajian Syariah dan Islam, University of the United Arab Emirates, 28 April, 2015.

'Abd al-Ilāh bin Mazrū' al-Mazrū', 'Aqd al-Ziwāj 'Abr al-Intarnit. t.tp.: t.p. t.t

'Alā' al-Dīn Abī Bakr Ibn Mas 'ūd al-Kasānī Badā 'i ' al-Sanā 'i ' Fī Tartīb al-Syarā' $i$ ', ed. Syeikh 'Alī Muḥammad dan Syeikh 'Ādil Ahmad. Cetakan Kedua. Bayrūt: Dār al-Kutub al'Ilmiyyah. Juzuk 3, 2003. 
'Alā' al-Dīn Bin Balbān al-Fārisī. Al-Ihsā̄n F̄̄ Taqrīb Șaḥīh Ibn Hibbān. Ed Markaz al-Buhūth Wa Taqniyah al-Ma'lūmāt. Cetaka Pertama. Bayrūt: Dār al-Ta’ṣīl. Jld. Kelima, 2014.

Abū 'Abd al-Raḥmān Aḥmad Bin Syu'ayb Al-Nasā’̀̄, Al-Sunan al-Kubrā. Ed. Hasan 'Abd al-Mun'im. Cetakan Pertama. Beirūt: Mu’assasah al-Risālah. Juzuk 3, 2001

Abū 'Abdullāh Muḥammad Bin Muḥammad Bin 'Abd al-Raḥmān Al-Hatțābī , Mawāhib al-Jalīl Li Syarh Mukhtașar Khalīl. Ed. Zakariyā 'Amīrāt. Beirūt: Dār 'Ālim al-Kutub. Juzuk Kelima. 2003.

Abū al-'Abbās Aḥmad Bin Muḥammad al-Ṣāwī , Bulghah al-Sālik li Aqrab al-Masālik (Hāsyiah al-Sāwī 'Alā Syarh al-Saghīr. T.tp., Dār al-Ma‘ārif, Juzuk 2, (t.t)

Abū al-Walīd Muhammad Bin Aḥmad Bin Muhammad Bin Rusyd, Bidāyah al-Mujtahid wa Nihāyah al-Muqtașid. Ed. Muḥammad Subḥī Hạan Ḥalāq. Cetakan Pertama. Qāhirah: Maktabah Ibn Taymiyyah. Jld. Ketiga,1995.

Ḥāfiz al-Dīn al-Nasfī (1997). Al-Baḥr al-Rā'iq Syarh Kanz alDaqā'iq (Fì Furū' al-Hanafiyah). Cetakan Pertama. Beirūt: Dār al-Kutub al-'Ilmiyyah. Juzuk Ketiga, 1997.

http://e-smaf.islam.gov.my/e-smaf/fatwa/fatwa/find/pr/12419 diakses 12 Disember 2020

https://alwafd.news/- أخبار -وتقارير / 822251-الإفتاء_تحذر _من-زواج_الفيديو diakses pada 15 Mac 2021

https://arabic.cnn.com/middleeast/2015/03/05/egypt-fatwavideo-conf-marriage diakses pada 10 September 2020

https://islamqa.info/ar/answers/2201/ diakses pada 1Jun 2021

Ibrāhīm Fāḍil al-Dabw. "Hukm Ijrā’ al-'Uqūd Bi Ālāt al-Ittișāl alHadīthah". Majlah Majma' al-Fiqh al-Islāmī. ed. Usamah Bin Zahra'. Jld.. 6, t.t.

Jabatan Kemajuan Islam Malaysia, Isu-Isu Fatwa Munakahat Keputusan Muzakarah Jawatankuasa Fatwa Majlis Kebangsaan Bagi Hal Ehwal Ugama Islam Malaysia. Cetakan Pertama. W.P Putrajaya: JAKIM, 2013. 
Jalāl al-Dīn 'Abd al-Rahmān al-Suyūṭị, Al-Asybāh wa al-Nazāa' ir Fì Qawā' 'id wa Furū' Fiqh al-Syāfi 'iyyah, Cetakan Pertama Beyrūt: Dār al-Kutub al-'Ilmiyyah, 1983.

Jalāl al-Dīn Muḥammad Bin Aḥmad Bin Muḥammad Jalāl alDīn Muḥammad Bin Aḥmad Bin Muḥammad Al-Maḥallī, Kanz al-Rāghibīn Syarh Minhāj al-Țālibìn. Cetakan Kedua. Jeddah: Dār al-Minhāj. Jld. Kedua, 2013

Kamaruddin, M.A. "Marriage Contact Using The Internet." Malaysian Jurnal of Syariah and Law 7 (2018), 227-258.

Keputusan Mesyuarat Jawatankuasa Fatwa Negeri Selangor Bil 1/2016, bersidang pada 19 Januari 2016.

Al-Lajnah al-Dā'imah Li al-Buhūth al-'Ilmiyyah Wa al-Iftā', Fatāwā Al-Lajnah al-Dā'imah Li al-Buhūth al-'Ilmiyyah Wa al-Iftā'. Ed. Syeikh Ahmad bin 'Abd al-Razzāq alDuwaysy. Riyāḍ: Mu’assasah al-Amīrah. Jld. 9, 2018.

Majma' al-Fiqh al-Islāmī al-Sa'ūdī, Bil: 52 (3/6) [1], Ḥukm Ijrā' al-'Uqūd Bi Ālāt al-Ittișāl al-Ḥadīthah.

Mansur Ibn Yūnus Ibn Idrīs al-Bahūtī, Sharh Muntahā al-Irādāt al-Musammā Daqā'iq Ūlì al-Nuhā li Sharh Muntahā. Cetakan Pertama. Bayrūt: 'Ālim al-Kutub, Juzuk Kedua, 1993.

Mufīdah 'Abd al-Wahhāb Muḥammad Ibrāhīm. "Hukm Ijrā' 'Aqd al-Nikāḥ "Abr al-Wasā’il al-Iliktrūniyyah al-Hadīthah." Majallah Kulliyah al-Syarī'ah wa al-Qanūn 20, no. 2, (2018), 1219-1248.

Muhammad 'Uqlah. "Hukm Ijrā' al-'Uqūd 'Abr Wasā'il al-Ittiṣāl.” Majallah al-Syarì'ah 5 (1986).

Muhammad Abū Zuhrah. al-Aḥwāl al-Shakhșiyah. Cetakan Ketiga. t.t.p.: Dār al-Fikr al-'Arabī, 1958.

Muhammad Amīn Ibn 'Ābidīn, Radd al-Mukhtār 'Alā al-Durr alMukhtār Sharh Tanwīr al-Abșār, ed. Syeikh 'Ādil Ahmad 'Abdul Mawjūd dan Syeikh 'Alī Muhammad Mu'awwaḍ. Riyāḍ: Dār 'Ālim al-Kutub. Juzuk 4, 2003.

Muḥammad Ibn Yaḥyā al-Najīmī. Hukm Ibrām 'Uqūd al-Aḥwāl al-Syakhșiyyah Wa al- 'Uqūd al-Tijāriyyah 'Abr Wasā'il alIliktrūniyah. t.t.p.: t.p., t.t. 
Muḥammad Khalaf Muḥammad Ban̄̄ Salāmah. "Masyrū'iyyah 'Uqūd al-Ziwāj Bi al-Kitābah 'Abr al-Internet". Majallah al-Jāmi 'ah al-Islāmiyyah Li al-Dirāsāt al-Islāmiyyah, jld 12, no. 2 (2014), 509-535,

Muhy Al-Dīn Abī Zakariyyā Bin Syaraf Al-Nawawī, Rawḍh alTạlibīn Wa 'Umdah al-Muftīn. Cetakan Ketiga. Bayrūt: AlMaktab al-Islāmī. Juzuk Ketujuh, 1991.

Muḥy al-Dīn Abī Zakariyyā Ibn Sharf al-Nawawī. al-Majmū' Sharh al-Muhadhdhab. Madīnah: al-Maktabah alSalafiyyah. Jld. 9, t.t

Mușțafā Bin Sa'd Bin 'Abduh al-Suyūṭī al-Rahịibānī. Mațālib Ūlì al-Nuhā fi Sharh Ghāyah al-Muntahā. Bayrūt: al-Maktab al-Islāmī. Juzuk 5,1994.

Raihanah Hj Azahari. "Kedudukan Mazhab Syafi'i dalam Undang-Undang Keluarga Islam: Satu Realiti." Jurnal Fiqh 4 (2007), 257-258.

Șāliḥ̄, "Abd al-Rahīm. "In“iqād al-Ziwāj bi al-Barīd al-Iliktrūn̄̄ Dirāsah Muqāranah Bayna al-Fiqh al-Islāmī wa al-Qānūn al-Jazā'irī." Majallah al-Dafātir al-Siyāsah wa al-Qānūn (Journal of Politic and Law) 7 (2012), 189-196.

Shams al-Dīn Bin Muhammad Bin Muhammad al-Khațīb alSyarbīn̄i. Mughnī al-Muhtāj Ilā Ma 'rifah Ma 'ānī Alfāz alMinhāj, ed. 'Alī Muhammad Mu'awwaḍ dan 'Ādil Aḥmad 'Abd al-Mawjūd. Bayrūt: Dār al-Kutub al-'Ilmiyyah. Juzuk 4, 2000.

Shams al-Dīn Bin Muhammad Bin Muhammad al-Khațīb alSyarbīnī. al-Iqnā' fì Hilli Alfāz Abī Shujā'. Eds, 'Alī Muḥammad Mu'awwaḍ dan 'Ādil Aḥmad 'Abd al-Mawjūd. Cetakan Ketiga. Bayrūt: Dār al-Kutub al-'Ilmiyyah. Juzuk 2, 2004

Usāmah 'Umar Sulaymān al-Asyqar. Mustajiddāt Fiqhiyyah F̄̄ Qậāya al-Ziwāj wa al-Talāq. Cetakan Pertama. Jordan: Dār al-Nafă'is, 2000.

Wan Mohamed Radzi, C., \& dan Bakar, O. "Teknologi Menurut Perspektif Barat dan Islam." Jurnal Usuluddin 3 (1996), 147-155. 
Zayn al-Dīn Bin Ibrāhīm Bin Muḥammad Ibn Nujaym. al-Baḥr al-Rā'iq Syarh Kanz al-Daqū ’iq. Cetakan Kedua. Qāhirah: Dār al-Kitāb al-Islāmī, Juzuk 3, t.t.

Al-Zuhaylī, Muhammad. al-Mu'tamad fì al-Fiqh al-Shāfi ‘̀̄. Cetakan Ketiga. Damsyiq: Dār al-Qalam. Juzuk Keempat, 2011.

Al-Zuhaylī, Wahbah. "Hukm Ijrā' al-'Uqūd Bi Ālāt al-Ittișāl alHadīthah". Majallah Majma 'al-Fiqh al-Islāmī. ed. Usāmah Bin Zahra'. Jld. 6, t.t.

Al-Zuhaylī, Wahbah. al-Figh al-Istāmī wa Adillatuh, Cetakan Kedua. Damsyiq: Dār al-Fikr. Jld. 7, 1985. 